Southern Illinois University Carbondale

OpenSIUC

Publications

Department of Geography and Environmental

Resources

2006

\title{
An Evaluation of Two GCMs: Simulation of North American Teleconnection Indices and Synoptic Phenomena
}

Justin T. Schoof

Southern Illinois University Carbondale, jschoof@siu.edu

S C. Pryor

Indiana University Bloomington

Follow this and additional works at: http://opensiuc.lib.siu.edu/gers_pubs

Part of the Physical and Environmental Geography Commons

Copyright 2005 Royal Meteorological Society. International Journal of Climatology, 26: 267-282

(2006). Published online 7 November 2005 in Wiley InterScience (www.interscience.wiley.com).

DOI: $10.1002 /$ joc. 1242

\section{Recommended Citation}

Schoof, Justin T. and Pryor, S C. "An Evaluation of Two GCMs: Simulation of North American Teleconnection Indices and Synoptic Phenomena." (Jan 2006).

This Article is brought to you for free and open access by the Department of Geography and Environmental Resources at OpenSIUC. It has been accepted for inclusion in Publications by an authorized administrator of OpenSIUC. For more information, please contact opensiuc@lib.siu.edu. 


\title{
AN EVALUATION OF TWO GCMs: SIMULATION OF NORTH AMERICAN TELECONNECTION INDICES AND SYNOPTIC PHENOMENA
}

\author{
J. T. SCHOOF* and S. C. PRYOR \\ Atmospheric Science Program, Department of Geography, Indiana University, Bloomington, IN 47405-7100, USA
}

\author{
Received 11 November 2004 \\ Revised 4 February 2005 \\ Accepted 21 June 2005
}

\begin{abstract}
We evaluate the ability of two coupled atmospheric-oceanic GCMs - the Hadley Center's third generation coupled climate model (HadCM3) and the Canadian Center for Climate Modeling and Analysis second-generation coupled model (CGCM2) - to simulate the North Atlantic Oscillation (NAO), the Pacific North American teleconnection pattern (PNA), and map patterns in the Midwest region of the United States, relative to NCEP/NCAR reanalysis (NNR) data. The observed (NNR-derived) and GCM-derived probability distributions and temporal behavior of the daily teleconnection indices exhibit agreement over the 1990-2001 reference period, and both GCMs successfully reproduce the range of 500-hPa map patterns over the study region. During the reference period, observed and modeled map patterns are similar in terms of frequency, coherence, persistence, and progression, although the most common map pattern occurs too often in HadCM3 relative to NNR and CGCM2-derived map patterns generally exhibit closer agreement with those derived from NNR data. Despite the relatively high degree of correspondence between the observed and simulated teleconnection indices and map patterns in the study area, differences between the GCM and NNR-derived map-pattern frequencies in the reference period are greater than either (1) recent historical changes in map-pattern frequencies or (2) changes in the mappattern frequencies as derived from twenty-first century GCM simulations, indicating that changes in these phenomena over recent and approaching decades are of insufficient magnitude relative to model uncertainty to be definitively identified. Copyright (c) 2005 Royal Meteorological Society.
\end{abstract}

KEY WORDS: GCM evaluation; PNA; NAO; Midwest USA

\section{INTRODUCTION}

\subsection{Background}

A key component of the IPCC Third Assessment Report (TAR; IPCC, 2001) was the evaluation of the suitability of coupled atmospheric-oceanic global climate models (AOGCMs, referred to herein as GCMs) for use in climate change projection and detection/attribution studies. Systematic comparison of several GCMs and evaluation against reanalysis data indicated that coupled models can provide credible simulations of the present annual mean climate and the climatological seasonal cycle over broad continental scales and are suitable tools to provide climate projections for the future (McAveney et al., 2001). However, the IPCC summary and other GCM evaluation studies (e.g. Coupled Model Intercomparison Project (CMIP), Covey et al., 2003) have generally focused on spatial scales larger than subcontinental and seasonal to decadal temporal scales. Due to the relatively coarse spatial resolution of GCMs, development of regional scale climate prognoses typically requires application of downscaling tools, which rely upon accurate GCM simulation of large-scale climate features at temporal scales relevant to climate change impacts research. If these features are not realistically simulated within GCMs at the required timescale, the downscaled climate information

* Correspondence to: J. T. Schoof, Center For Ocean-Atmospheric Prediction Studies, The Florida State University, Tallahassee, FL, 32306-2840, USA; e-mail: schoof@coaps.fsu.edu 
will likewise be invalid. Indeed, Pan et al. (2001) demonstrated in their analysis of dynamically downscaled hydrologic regimes that uncertainties resulting from biases in GCM boundary conditions were comparable to those arising from variations between the regional climate models forced with the GCM. Hence, there is a need to extend GCM evaluation of large-scale phenomena to the subcontinental spatial scale and daily timescale to assess the confidence with which we can view climate projections at the scales needed for impacts research, and to identify parameters or processes that are not well simulated in order to infer aspects of the GCMs that may require improvement.

In this paper, a detailed evaluation of GCM-simulated teleconnections, the North Atlantic Oscillation (NAO) and Pacific/North American pattern (PNA), and synoptic-scale map patterns is presented and others are being considered under the Atmospheric Model Intercomparison Project (AMIP) (Gates et al., 1999; Kang et al., 2002) and the Coupled Model Intercomparison Project (CMIP) (Stephenson and Pavan, 2003). By choosing the size of our region at the lower end of the synoptic scale, we aim to evaluate the GCM simulations at the smallest scale at which they are generally considered robust. While it must be acknowledged that accurate simulations of the mean or variability of a parameter by a GCM need not necessarily reflect an accurate model formulation, it is asserted that deviations from observations can be used to identify potential model weaknesses and to provide uncertainty bounds for use in assessing prognostic changes in those parameters relative to the current day.

In one of the first evaluations of synoptic-scale phenomena in GCM simulations, McKendry et al. (1995) used a Kirchhofer correlation-based classification to test the ability of the Canadian Climate Center's secondgeneration atmospheric GCM to reproduce the current climate of Western Canada. They found that the model reproduced the synoptic types, but that seasonal frequencies and their variability were not accurately simulated. More recent comparisons have shown greater robustness of GCMs with respect to the synoptic scale (Schubert, 1998; Lapp et al., 2002), but relatively few studies have focused on this scale, and model evaluation results are regionally and seasonally variable.

Coupled GCMs generally simulate the NAO quite well (McAveney et al., 2001) and have been shown to reproduce the slight serial correlation present in observations on an annual timescale $(r<0.3$ for successive winters) (Stephenson and Pavan, 2003). However, several models have been shown to exhibit unrealistic monotonic trends in the NAO and/or overly strong correlations with the El Niño-Southern Oscillation (ENSO) (Stephenson and Pavan, 2003). Previous analyses of NAO simulation by GCMs have focused primarily on the spatial representation of the phenomenon and temporal behavior over interannual and longer timescales (Osborn et al., 1999; Stephenson and Pavan, 2003). However, Stephenson and Pavan (2003) show that the NAO signal is dominated by short-term variations and state that more than $70 \%$ of the NAO variance is explained by fluctuations with periods of less than a decade.

Comparatively few studies have quantified the ability of GCMs to accurately simulate the PNA. Several atmospheric GCMs have been shown to underestimate the amplitude of the PNA pattern associated with the 1997-1998 El Niño event (Kang et al., 2002), although Renshaw et al. (1998) showed that HadAM3, the atmospheric component of HadCM3, correctly reproduces the changes in the frequency distribution of the PNA index associated with the phases of ENSO. As with the NAO, most studies of the PNA have focused on interannual and longer timescales, although the PNA varies on all timescales from days to decades (Blackmon et al., 1984; Yarnal and Leathers, 1988).

In this study, we extend previous NAO and PNA research by focusing on shorter timescales, allowing examination of short-term variability in the teleconnection indices and their relationships with daily circulation patterns in the study region.

\subsection{Objectives}

The primary objective of this study is to evaluate the simulation of two teleconnections and synopticscale map patterns in the Midwest region of the United States within two GCMs: the Hadley Center's third generation coupled climate model, HadCM3 (Gordon et al., 2000; Pope et al., 2000), and the Canadian Center for Climate Modeling and Analysis second-generation coupled climate model, CGCM2 (Flato et al., 2000; Flato and Boer, 2001), relative to NCEP/NCAR reanalysis (NNR) data (Kalnay et al., 1996; Kistler et al., 
2001). We also examine the linkages between the teleconnection indices and map patterns, by evaluating the relative frequencies of the dominant map patterns under positive and negative teleconnection phases. The evaluation is conducted for the 1990-2001 reference period, which is dictated by the period of overlap between the NNR data and GCMs, and observed discrepancies are considered in the context of changes over recent decades and potential twenty-first century changes projected by the GCMs. An additional objective is to examine the teleconnections and map patterns generated by HadCM3 and CGCM2 for approaching decades relative to changes documented over the latter portion of the observed climate record. This comparison provides a mechanism for determining the confidence with which we can view prognostic climates for this region, as derived from these GCMs.

\section{DATA}

The NNR project was designed to provide homogenized gridded records to support climate research. The system combines data from a range of sources in an assimilation scheme to produce temporally continuous atmospheric fields for the period from 1948 to the present. The data used here are archived at a resolution of $2.5^{\circ} \times 2.5^{\circ}$ (Figure 1). In this study, we average twice-daily NNR 500-hPa geopotential height fields to produce daily fields from which the PNA index and map patterns for the study region are derived. Daily mean sea-level pressure (SLP) fields are used to compute the NAO index.

This study also uses daily output from transient climate simulations conducted using the two GCMs; HadCM3 (1990-2099) and CGCM2 (1990-2100). The atmospheric component of HadCM3 has 19 levels with a horizontal resolution of approximately $2.5^{\circ}$ latitude $\times 3.75^{\circ}$ longitude. CGCM2 has 10 vertical levels, with a horizontal resolution of approximately $3.75^{\circ}$ latitude $\times 3.75^{\circ}$ longitude. The model grid points from each GCM are shown in Figure 1. Prior to application of the map-pattern classification, both GCM grids were interpolated to the $2.5^{\circ} \times 2.5^{\circ} \mathrm{NNR}$ grid using an inverse distance-based interpolation algorithm. Using a cross-validation procedure, we estimated the interpolation errors for $500-\mathrm{hPa}$ geopotential height to be in the range of 6 to $9 \mathrm{~m}$ for both GCMs. Both GCM simulations used here are conducted using the SRES A2 emissions scenario (IPCC, 2000), which results in global $\mathrm{CO}_{2}$ emissions from industry and energy in 2100 that are almost four times the 1900 value, and emissions from land use change by 2100 are close to zero, leading to a global $\mathrm{CO}_{2}$ emission in 2100 of almost $28 \mathrm{GtC} \mathrm{yr}^{-1}$. This emissions scenario is used in this

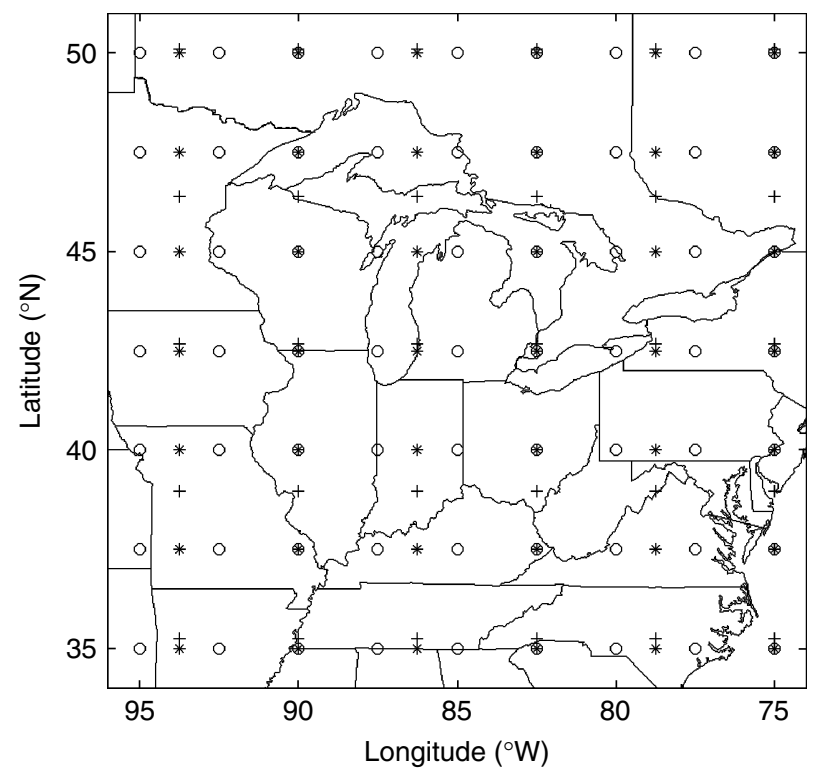

Figure 1. Map of the study region showing NNR (O), HadCM3 (*) and CGCM2 (+) grid points 
analysis to provide an upper bound on likely climate change and hence a high signal to noise ratio when comparing current to future teleconnection indices and map patterns.

In this study, the NAO is defined in terms of the difference in standardized SLP between grid points near the NAO centers of action, at Ponta Delgada, Azores $\left(37.7^{\circ} \mathrm{N}, 25.7^{\circ} \mathrm{W}\right)$ and Stykkisholmur, Iceland $\left(65.1^{\circ} \mathrm{N}\right.$, $22.7^{\circ} \mathrm{W}$ ), while the PNA index is computed using the equation of Wallace and Gutzler (1981):

$$
P N A=\frac{1}{4}\left[Z\left(20^{\circ} \mathrm{N}, 160^{\circ} \mathrm{W}\right)-Z\left(45^{\circ} \mathrm{N}, 165^{\circ} \mathrm{W}\right)+Z\left(55^{\circ} \mathrm{N}, 115^{\circ} \mathrm{W}\right)-Z\left(30^{\circ} \mathrm{N}, 85^{\circ} \mathrm{W}\right)\right]
$$

where $Z$ is the standardized (by season within the study period) 500-hPa geopotential height value. Results of compositing analyses (not shown) indicate that these locations represent accurate proxies for the NAO and PNA centers of action in both the NNR and GCMs. Because NNR, HadCM3, and CGCM2 output are archived at different resolutions, output from all data sources was interpolated to the appropriate locations for calculation of the indices. We focus our analysis of the NAO exclusively on winter (DJF) when it is most dominant (Barnston and Livezey, 1987) and standardize our index using winter means and standard deviations. Likewise, the PNA is not a major mode of the Northern Hemisphere circulation during the summer (Barnston and Livezey, 1987), but exhibits statistically significant relationships with US temperatures during the winter, spring, and autumn (Leathers et al., 1991). Hence, we exclude summer from our analysis of the PNA. Normalized NAO and PNA indices from the GCMs and NNR (where each is normalized to the specific model values) are compared here because we wish to focus on the relative behavior of the centers of action rather than the absolute values at the station locations.

\section{METHODOLOGY}

\subsection{Evaluation of large-scale teleconnection indices}

Successful simulation of the teleconnection indices by the GCMs requires that the models can reproduce the distribution of the daily teleconnection index values, as well as their evolution. To evaluate the former, probability distributions of the daily indices are compared using a two-sample Kolmogorov-Smirnov $(\mathrm{K}-\mathrm{S})$ goodness-of-fit test (see Wilks, 1995) under the null hypothesis that the daily teleconnection indices from the NNR and GCMs are drawn from the same distribution. The K-S test statistic is the largest absolute difference between empirical cumulative distribution functions (ECDFs). For each test, effective sample sizes (see von Storch and Zwiers, 1999) are computed to account for the autocorrelation in the daily teleconnection indices. The evolution of the daily teleconnection indices is evaluated using correlograms, which depict the correlation between time series values separated by lags of 1-10 days. Differences in the autocorrelation in the NNR- and GCM-derived teleconnection time series are tested for statistical significance using Fisher's z test.

The period of standardization plays a critical role in the calculation of teleconnection indices. Hence, when comparing NNR and GCM-simulated teleconnection indices for the period 1990-2001, we standardize the data using the 1990-2001 seasonal means and standard deviations from the NNR or GCMs. To place the differences between observed and simulated teleconnection indices in context, we also examine their magnitude relative to recent and possible future changes in the teleconnection indices. Thus, for historical analyses, the indices are standardized using 1954-2001 seasonal means and standard deviations, while for analysis of GCM projections, data are standardized using 1990-2099 (HadCM3) or 1990-2100 (CGCM2) seasonal means and standard deviations.

\subsection{Synoptic-scale map-pattern analysis}

Several methodologies can be applied to develop synoptic-scale circulation classifications (Yarnal, 1993). In this study, we use correlation-based methods because they are readily amenable to (1) development of targeted classifications for the GCM output relative to the NNR and (2) comparison of the NNR and GCM 
classifications using bootstrapping techniques to develop confidence intervals for the mean seasonal mappattern frequencies. The former allows direct comparison of the NNR- and GCM-derived classifications, while the latter facilitates application of quantitative statistical tools to assess differences in the classifications.

Correlation-based methods of synoptic-scale weather classification have been widely used since their introduction by Lund (1963), who classified map patterns using the Pearson product-moment correlation of gridded fields. Kirchhofer (1974) improved on the correlation-based map typing technique by requiring that sub-map scale patterns also meet the correlation threshold (El-Kadi and Smithson, 1992). The Kirchhofer score of similarity, S, for two grid point maps is simply the sum of squared differences of the normalized grid point values and can be easily transformed to a correlation coefficient using the expression given by Willmott (1987). By setting a threshold for the required correlation, an appropriate threshold for S can be determined. It is then necessary to calculate $\mathrm{S}$ for all combinations of pairs of observations being classified. Subgrid scale similarity is ensured by also requiring each of the rows and columns of the grids to meet the similarity criteria. The observation with the maximum number of threshold exceedances is referred to as the first key day. This key day and all similar observations are then removed from the analysis. All days similar to those days are also removed. This process is then repeated until there are no more days left. Once all of the key days have been identified, each observation that has been removed is assigned to the key day for which it has the highest $\mathrm{S}$ value.

Different thresholds for grid and subgrid similarity and minimum group size have previously been applied for different variables (Yarnal, 1985; McKendry et al., 1995). In this study, the correlation threshold for the entire grid is set at 0.75 , the individual row and column thresholds are set at half of the entire grid threshold (0.375), and the map-pattern groups are required to have more than five members. These values are chosen to ensure a manageable number of weather types and a high percentage of classified days.

To evaluate the ability of the two GCMs to represent the circulation regimes of the study area, we apply the Kirchhofer method to the NNR 500-hPa geopotential heights fields for the period of overlap with the GCMs (1990-2001). Viewing the 1990-2001 NNR results as one possible realization of the current climate, other potential realizations are extracted using a bootstrap resampling method (Efron, 1982) to generate a 'climatology' comprising 1000 random samples of this 12-year period, which are presented in the form of confidence intervals for the means and standard deviations of map-pattern frequencies.

Targeted Kirchhofer classifications are subsequently applied to HadCM3 and CGCM2 output for 1990-2001. In each targeted classification, the key days identified in the 1990-2001 NNR are used as seeds and the classification procedure is the same as that previously described. Use of the targeted classifications facilitates quantitative comparisons between observations (NNR) and simulations (GCMs) to determine whether differences in the NNR and GCM synoptic regimes result from differences in the map patterns or differences in the frequencies with which the map patterns are observed. In addition to the seasonal map-pattern frequencies, the analysis of the map patterns also includes an examination of the persistence of individual map patterns, which is defined as the average run length, and the progression from one map pattern to another, which is examined by tabulating the map patterns which most commonly precede each of the identified map patterns.

To place the differences between NNR and the GCMs in context, we examine their magnitude relative to recent changes in NNR and potential future changes as simulated by the GCMs. For the former, NNR map-pattern frequencies from historical periods (1954-1965, 1966-1977, and 1978-1989) are compared to the NNR 1990-2001 bootstrap confidence intervals. For the latter, we construct bootstrap confidence intervals using the 1990-2001 GCM data and then compute the mean map-pattern frequencies for future GCM periods: 2002-2013, 2014-2025, 2026-2037, 2038-2049, 2050-2061, 2062-2073, 2074-2085, and 2086-2097.

\subsection{Relationships between teleconnections and midwest US weather types}

Using the NAO and PNA indices described above, the frequency of each correlation-based map pattern is determined for each phase of the NAO and PNA. Each day is assigned as either positive (more than one standard deviation greater than the seasonal mean of the teleconnection), negative (more than one standard deviation less than the seasonal mean of the teleconnection), or neutral (within one standard deviation of the 
seasonal mean of the teleconnection). The strength of the link between the teleconnections and map patterns is then determined by comparing the frequency of the map-pattern occurrence during the positive and negative phases of the teleconnections.

To quantify variations in the links between the teleconnection indices and the map patterns, a two-sample difference of proportions test (Ott, 1993; Sheridan, 2003) was applied to the proportions of positive and negative phase days for each teleconnection using a $z$-score. Proportions that result in a large absolute $z$-score (e.g. not expected to occur more than $5 \%$ of the time if the proportions are the same) suggest that a particular map pattern is more likely to occur in either the positive or negative phase of the teleconnection.

\section{RESULTS}

\subsection{Teleconnection indices}

4.1.1. North Atlantic Oscillation (NAO). The $\mathrm{K}-\mathrm{S}$ test statistics for the probability distributions of the reference period (1990-2001) NNR, HadCM3, and CGCM2 winter NAO index do not warrant rejection of the null hypotheses that the observed and simulated indices are drawn from the same underlying distribution at the $\alpha=0.05$ level (Table I). Further, each model correctly simulates the strong lag-1 autocorrelation present in the daily NNR data (Figure 2(a)), although both GCMs, and particularly CGCM2, overestimate the autocorrelation at lags greater than 1. The differences between the observed and simulated autocorrelations are not significant, according to Fisher's z statistic.

To examine the temporal evolution of the NAO and provide a context for the differences between the NNR- and GCM-derived indices, the NAO index was calculated for 12-year segments of the observed

(a) NAO DJF

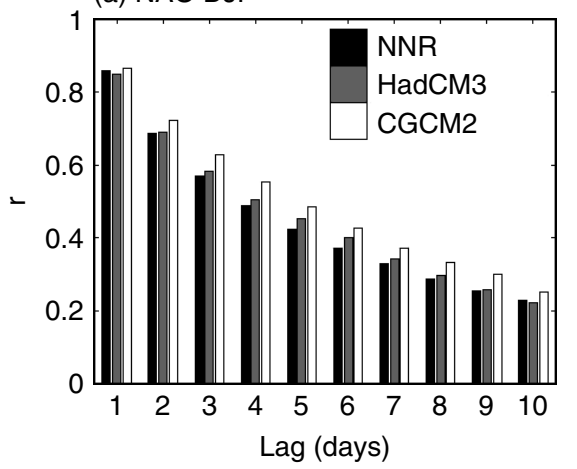

(c) PNA MAM

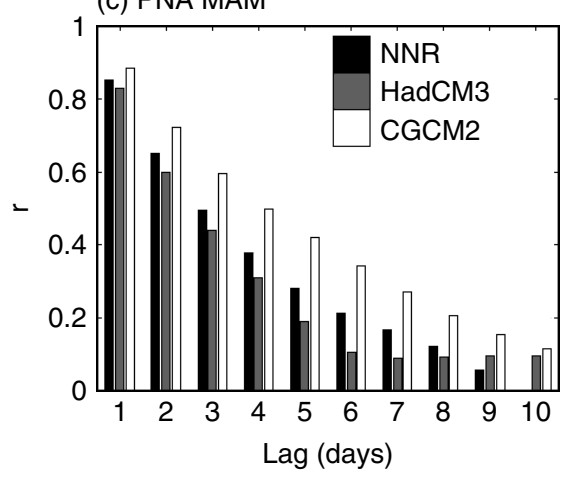

(b) PNA DJF

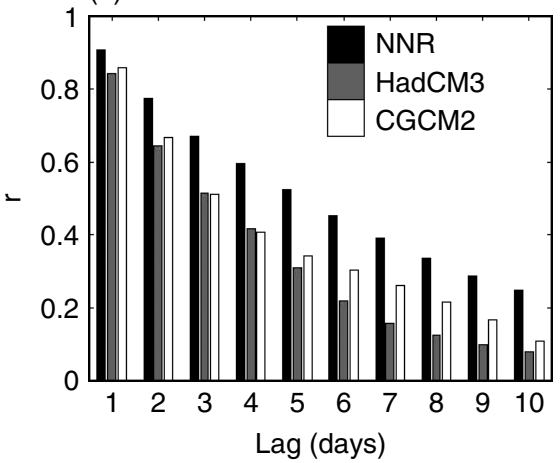

(d) PNA SON

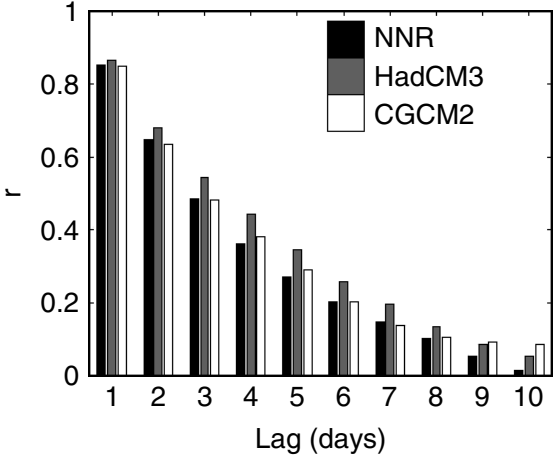

Figure 2. Correlograms depicting the seasonal correlation structure of the NAO and PNA from NNR and GCM simulations: (a) winter (DJF) NAO and (b) winter (DJF) PNA, (c) spring (MAM) PNA, (d) autumn (SON) PNA 
Table I. Results of the Kolmogorov-Smirnov tests performed on NNR-, HadCM3- and CGCM2-derived NAO and PNA indices. For each season and time period the table provides the $p$-values (i.e. the probability of observing a test statistic as extreme or more extreme than that observed if the null hypothesis is true) associated with the test. Table entries are in italics if statistically significant at $\alpha=0.05$

\begin{tabular}{|c|c|c|c|c|}
\hline \multicolumn{5}{|c|}{$\mathrm{K}-\mathrm{S}$ D-statistic ( $p$-value) } \\
\hline \multirow[t]{2}{*}{ Time Period } & \multirow{2}{*}{$\frac{\text { NAO }}{\text { DJF }}$} & \multicolumn{3}{|c|}{ PNA } \\
\hline & & DJF & MAM & SON \\
\hline NNR vs HadCM3 1990-2001 & $0.05(1.00)$ & $0.07(0.99)$ & $0.03(1.00)$ & $0.04(1.00)$ \\
\hline NNR vs CGCM2 1990-2001 & $0.02(1.00)$ & $0.07(1.00)$ & $0.04(1.00)$ & $0.05(1.00)$ \\
\hline NNR: 1990-2001 vs 1954-1965 & $0.16(0.34)$ & $0.09(0.96)$ & $0.24(0.02)$ & $0.05(1.00)$ \\
\hline NNR: 1990-2001 vs 1966-1977 & $0.14(0.38)$ & $0.14(0.62)$ & $0.21(0.04)$ & $0.04(1.00)$ \\
\hline NNR: 1990-2001 vs 1978-1989 & $0.09(0.87)$ & $0.07(1.00)$ & $0.06(1.00)$ & $0.05(1.00)$ \\
\hline HadCM3: 1990-2001 vs 2002-2013 & $0.14(0.27)$ & $0.12(0.44)$ & $0.03(1.00)$ & $0.11(0.63)$ \\
\hline HadCM3: 1990-2001 vs 2014-2025 & $0.13(0.45)$ & $0.06(1.00)$ & $0.03(1.00)$ & $0.03(1.00)$ \\
\hline HadCM3: 1990-2001 vs 2026-2037 & $0.06(0.99)$ & $0.16(0.19)$ & $0.05(1.00)$ & $0.04(1.00)$ \\
\hline HadCM3: 1990-2001 vs 2038-2049 & $0.06(1.00)$ & $0.06(1.00)$ & $0.06(0.99)$ & $0.05(1.00)$ \\
\hline HadCM3: 1990-2001 vs 2050-2061 & $0.03(1.00)$ & $0.06(1.00)$ & $0.09(0.76)$ & $0.06(1.00)$ \\
\hline HadCM3: 1990-2001 vs 2062-2073 & $0.15(0.22)$ & $0.13(0.55)$ & $0.09(0.88)$ & $0.05(1.00)$ \\
\hline HadCM3: 1990-2001 vs 2074-2085 & $0.04(1.00)$ & $0.20(0.05)$ & $0.16(0.18)$ & $0.15(0.30)$ \\
\hline HadCM3: 1990-2001 vs 2086-2097 & $0.08(0.90)$ & $0.07(0.99)$ & $0.10(0.74)$ & $0.14(0.53)$ \\
\hline CGCM2: 1990-2001 vs 2002-2013 & $0.06(1.00)$ & $0.11(0.69)$ & $0.05(1.00)$ & $0.03(1.00)$ \\
\hline CGCM2: 1990-2001 vs 2014-2025 & $0.05(1.00)$ & $0.01(0.81)$ & $0.08(0.99)$ & $0.03(1.00)$ \\
\hline CGCM2: 1990-2001 vs 2026-2037 & $0.07(0.99)$ & $0.10(0.78)$ & $0.04(1.00)$ & $0.03(1.00)$ \\
\hline CGCM2: 1990-2001 vs 2038-2049 & $0.09(0.90)$ & $0.04(1.00)$ & $0.12(0.70)$ & $0.06(0.99)$ \\
\hline CGCM2: 1990-2001 vs 2050-2061 & $0.05(1.00)$ & $0.17(0.13)$ & $0.17(0.24)$ & $0.06(1.00)$ \\
\hline CGCM2: 1990-2001 vs 2062-2073 & $0.06(1.00)$ & $0.17(0.16)$ & $0.24(0.03)$ & $0.07(0.99)$ \\
\hline CGCM2: 1990-2001 vs 2074-2085 & $0.11(0.58)$ & $0.29(0.00)$ & $0.27(0.02)$ & $0.17(0.15)$ \\
\hline CGCM2: 1990-2001 vs 2086-2097 & $0.10(0.75)$ & $0.24(0.02)$ & $0.38(0.00)$ & $0.21(0.05)$ \\
\hline
\end{tabular}

record (1954-1965, 1966-1977, and 1978-1989) and the GCM simulation periods (2001-2013, 2014-2025, 2026-2037, 2038-2049, 2050-2061, 2062-2073, 2074-2085, and 2086-2097). In accord with previous studies (e.g. Hurrell, 1995) and consistent with the established underlying trend in the north-south pressure difference in the Atlantic in the latter portion of the twentieth century (Pryor and Barthelmie, 2003), the NNRderived winter NAO index exhibits an increased prevalence of positive values toward the end of the twentieth century. While a $\mathrm{K}-\mathrm{S}$ test applied to the NAO index derived from different segments of the NNR historical data does not result in rejection of the null hypothesis (Table I), the $p$-values suggest that historical changes in the NAO probability distribution are much larger than the differences between NAO indices derived from the 1990-2001 NNR data and GCM simulations. Additionally, a $t$-test that assumes unequal variances and accounts for autocorrelation identifies a statistically significant difference (with $\alpha=0.05$ ) in the mean of the winter NAO index for 1990-2001 compared to 1954-1965.

Further examination of the historical winter NAO index indicates that different parts of the probability distribution have changed over time (Figure 3(a)). The overall increase between 1954-1965 and 1966-1977 resulted primarily from fewer large negative index values, while the relative frequency of positive NAO index values remained nearly stable. The change between 1966-1977 and 1978-1989 was due to fewer small negative index values and more large positive index values. The most recent change (between 1978-1989 and 1990-2001) resulted from fewer negative index days and more positive index days, consistent with a positive translation of the probability distribution (Figure 3(a)).

Application of the K-S test to the reference period (1990-2001) NAO index and future 12-year segments from HadCM3 and CGCM2 does not result in a rejection of the null hypothesis for any of the periods 

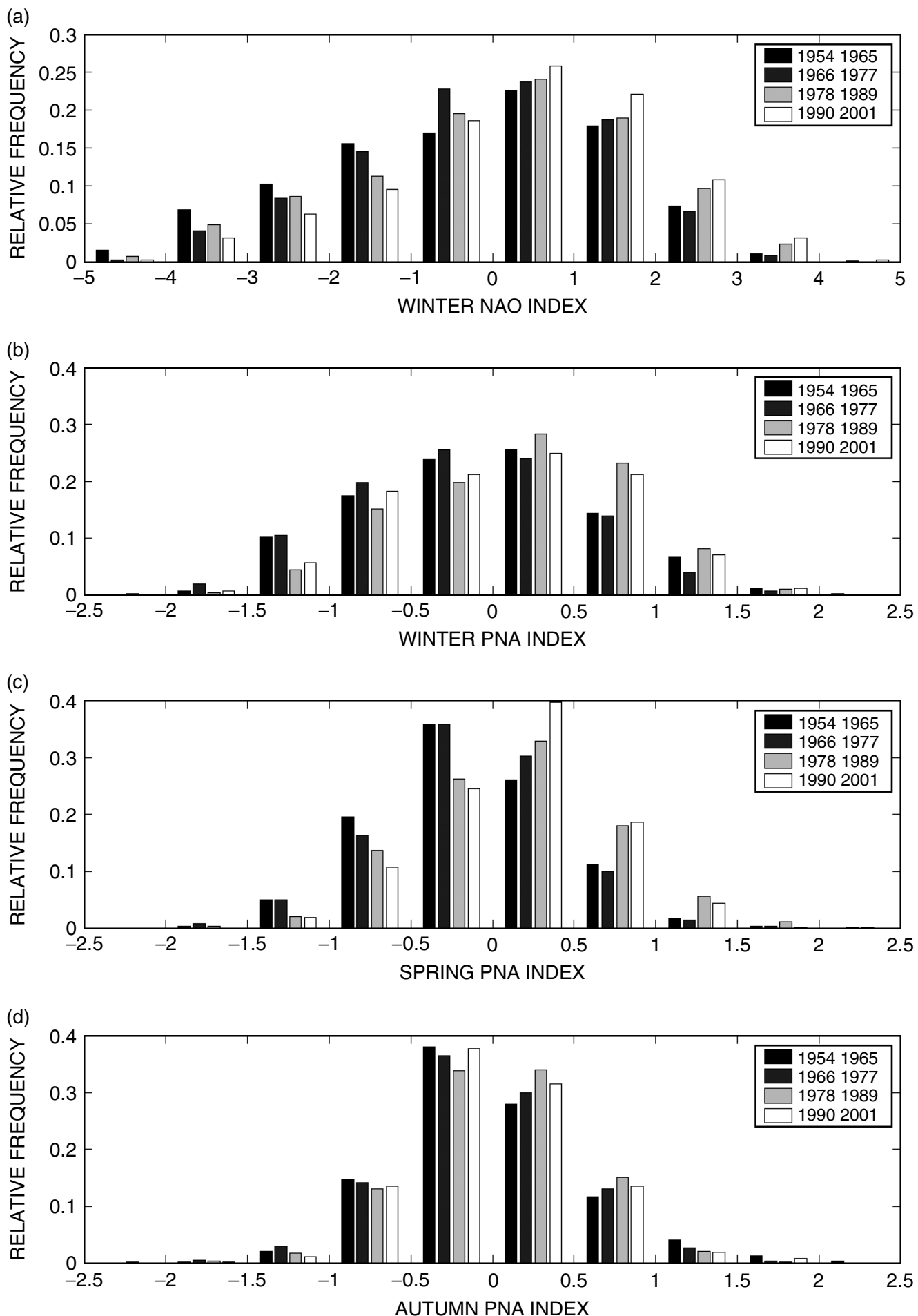

Figure 3. Probability distributions of the (a) winter (DJF) NAO, (b) winter (DJF) PNA, (c) spring (MAM) PNA, and (d) autumn (SON) PNA derived from NNR data. Recall that in the calculation of each index, data from the specific season for 1954-2001 were used in the index normalization 
considered (Table I). However, HadCM3 indicates a decrease in the probability of positive NAO values during the first quarter of the twenty-first century, an NAO probability distribution similar that of the 1990-2001 reference period during the middle of the twenty-first century, another decrease in the probability of positive NAO values during the 2060s, and a probability distribution again similar to that of the reference period for the last quarter of the twenty-first century. In contrast, the CGCM2-derived NAO index indicates little change in the teleconnection over the twenty-first century. The shift toward more positive NAO index values that occurs around 2075 is not statistically significant.

Based on the analyses presented above, we conclude that differences between observed and simulated probability distributions of the NAO index over the reference period (1990-2001) are smaller than both changes in the indices during recent decades and prognostic changes quantified using transient GCM output. The finding that HadCM3 does not suggest continued evolution toward higher north-south gradients across the Atlantic, and hence a more positive NAO index, is in accord with analyses in Osborn et al. (1999), which indicate that the positive trend in observed winter NAO from 1963 to 1992 is 'highly unusual' and that the HadCM2 winter NAO exhibited a decline from the 1990 level over the following decades. The discrepancy between CGCM2 and HadCM3 projections may be due to differences in the model treatment of atmosphere-surface interactions. Although the NAO has been reproduced in atmosphere-only GCMs (Glowienka-Hense, 1990), the oceans may provide the inertia for longer-term variability in the NAO (Osborn et al., 1999, Visbeck et al., 2003). While these models contain similarly discretized oceanic models, CGCM2 uses monthly heat and water flux adjustments, which may moderate the atmospheric response to changing oceanic conditions. These flux adjustments may influence the NAO realizations because while the NAO is particularly responsive to atmospheric forcing on the annual timescale, it is most sensitive to changes in oceanic circulation and sea-surface temperatures as well as snow cover within the North Atlantic sector and beyond on longer timescales (Kushnir, 1994; Hurrell and Van Loon, 1997; Tourre et al., 1999; Bojariu and Gimeno, 2003).

4.1.2. Pacific/North American (PNA) index. Application of the $\mathrm{K}-\mathrm{S}$ test to the reference period NNR and GCM-derived PNA indices does not result in the rejection of the null hypotheses that the seasonal PNA indices are drawn from the same underlying distribution. Each model also correctly simulates the strong lag-1 autocorrelation present in the NNR data, but the persistence of the PNA is underestimated by HadCM3 during winter and spring, and CGCM2 underestimates the persistence of the PNA during winter and overestimates the persistence of the PNA during spring (Figure 2). As with the NAO, these differences are not significant according to Fisher's z statistic.

According to the $\mathrm{K}-\mathrm{S}$ test, the distributions of the PNA indices derived from the NNR data for 1954-1965 and 1966-1977 differ from the 1990-2001 PNA distribution during spring (Table I, Figure 3(c)). Further examination of the historical spring PNA index indicates fewer negative index values and more positive index values concurrent with the increase in tropical Pacific sea-surface temperatures (i.e. the climate shift of the mid-1970s, see Stocker et al., 2001). Although not statistically significant, the distribution of the winter PNA index shifted to more positive values at the same time (Figure 3(b)).

Unlike the NAO, the projections of the PNA from HadCM3 and CGCM2 differ only slightly between the models, and neither model indicates substantial changes in the distribution of the PNA during the first half of the twenty-first century. In HadCM3, the only significant difference identified by the $\mathrm{K}-\mathrm{S}$ test occurs with a further positive shift in the winter PNA index during 2074-2085 (Table I), and, although not statistically significant, changes in the spring PNA index are also evident during the same period. In CGCM2, a positive shift in the PNA index distribution occurs slightly earlier, with statistically significant differences between the 1990-2001 and the post-2074 winter PNA index and between the 1990-2001 and post-2062 spring PNA index. Unlike HadCM3, CGCM2 also indicates an increase in the autumn PNA index (significant at $\alpha=0.10$, see Table I). These results, taken in concert with analyses by Leathers and Palecki (1992) who suggest that the 1957-1987 PNA index exhibited a bias toward positive values, may be indicative of a sustained prevalence of positive PNA values and hence, a more meridional circulation over the continental United States. 


\subsection{Synoptic-scale map-pattern analysis}

4.2.1. Observed map patterns: 1990-2001. Application of the Kirchhofer method (Section 3.2) to the 1990-2001 daily NNR 500-hPa geopotential height fields results in 15 map patterns accounting for 91.37\% of the observations. The key days for these map patterns are shown in Figure 4. Table II shows the frequency, mean correlation coefficient (a measure of within-class variability computed as the mean correlation between each key day and members of the class associated with the key day), persistence, and map-pattern progression for each map pattern. The correlations shown in Table II are much higher than the threshold of 0.75 , suggesting that this classification is robust.
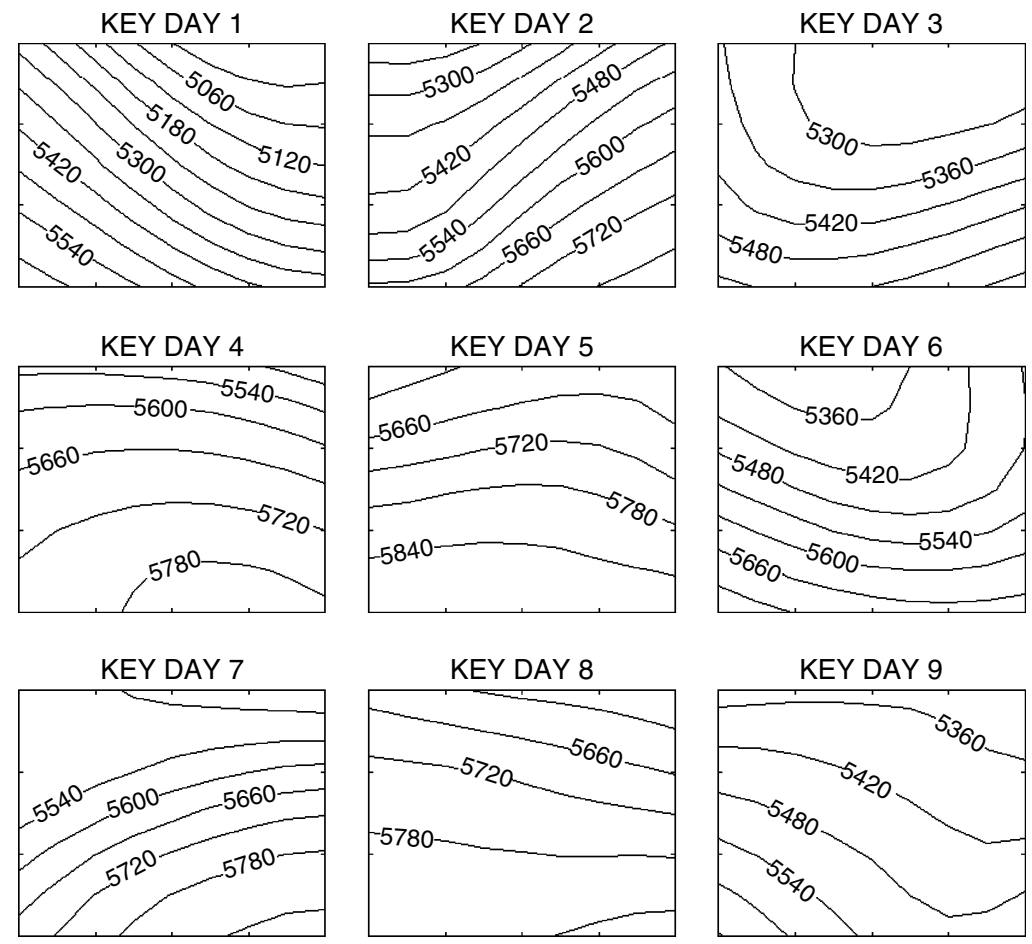

KEY DAY 10

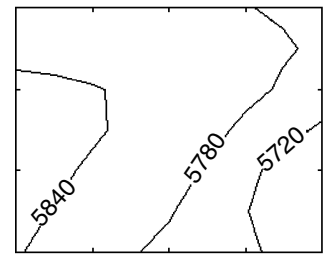

KEY DAY 13

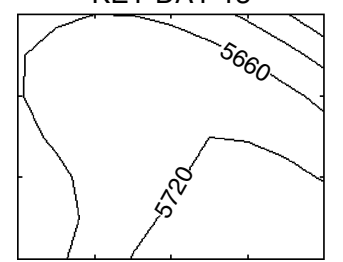

KEY DAY 11

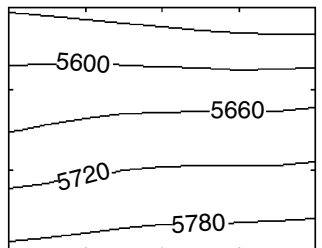

KEY DAY 14

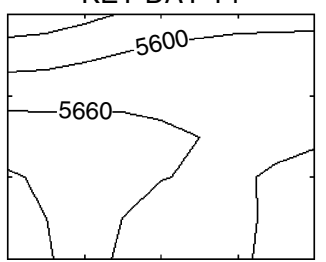

KEY DAY 12

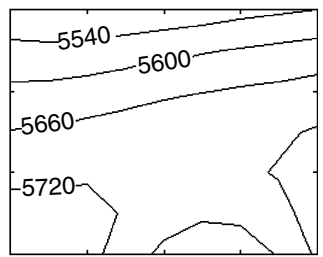

KEY DAY 15

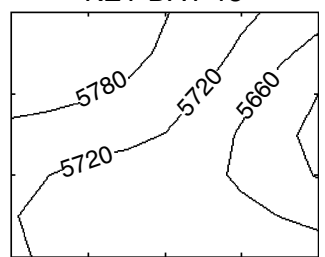

Figure 4. Key day maps for each of the 15 Kirchhofer map patterns associated with the 1990-2001 NNR 500-hPa geopotential height fields (in gpm). The domain is as shown in Figure 1 
Table II. Percentage frequency, mean correlation coefficient, mean persistence, and most commonly preceding map patterns for each of the 15 Kirchhofer map patterns identified from the 1990-2001 NNR, HadCM3, and CGCM2 500-hPa geopotential height fields

\begin{tabular}{|c|c|c|c|c|c|c|c|c|c|c|c|c|}
\hline \multirow[t]{2}{*}{$\begin{array}{l}\text { Map } \\
\text { pattern }\end{array}$} & \multicolumn{3}{|c|}{$\begin{array}{c}\text { Percentage } \\
\text { frequency }(\%)\end{array}$} & \multicolumn{3}{|c|}{$\begin{array}{c}\text { Mean correlation } \\
\text { coefficient }\end{array}$} & \multicolumn{3}{|c|}{$\begin{array}{c}\text { Mean persistence } \\
\text { (days) }\end{array}$} & \multicolumn{3}{|c|}{$\begin{array}{l}\text { Most commonly } \\
\text { preceding types }\end{array}$} \\
\hline & NNR & HadCM3 & CGCM2 & NNR & HadCM3 & CGCM2 & NNR & HadCM3 & CGCM2 & NNR & HadCM3 & CGCM2 \\
\hline 1 & 17.59 & 26.57 & 16.58 & 0.93 & 0.92 & 0.94 & 1.78 & 2.25 & 1.90 & $1,8,3$ & $1,3,8$ & $1,8,11$ \\
\hline 2 & 7.60 & 8.54 & 4.25 & 0.92 & 0.92 & 0.93 & 1.46 & 1.65 & 1.49 & $2,7,5$ & $2,7,4$ & $2,7,5$ \\
\hline 3 & 6.68 & 5.90 & 7.92 & 0.93 & 0.93 & 0.95 & 1.28 & 1.18 & 1.40 & $3,7,11$ & $7,2,11$ & $3,7,11$ \\
\hline 4 & 5.80 & 9.72 & 4.54 & 0.95 & 0.93 & 0.95 & 1.24 & 1.41 & 1.24 & $8,1,4$ & $4,1,8$ & $8,4,1$ \\
\hline 5 & 7.73 & 3.50 & 7.99 & 0.95 & 0.93 & 0.95 & 1.20 & 1.09 & 1.25 & $1,5,11$ & $1,4,9$ & $5,1,8$ \\
\hline 6 & 3.74 & 2.13 & 2.60 & 0.94 & 0.93 & 0.95 & 1.15 & 1.16 & 1.18 & $2,5,6$ & $2,5,8$ & $11,6,2$ \\
\hline 7 & 6.50 & 6.41 & 6.78 & 0.95 & 0.94 & 0.95 & 1.27 & 1.22 & 1.30 & $11,7,2$ & $11,4,7$ & $11,7,4$ \\
\hline 8 & 14.37 & 9.44 & 15.27 & 0.95 & 0.93 & 0.95 & 1.50 & 1.42 & 1.49 & $8,1,11$ & $8,1,11$ & $8,11,1$ \\
\hline 9 & 4.15 & 4.21 & 4.41 & 0.93 & 0.92 & 0.94 & 1.17 & 1.24 & 1.21 & $1,3,9$ & $1,9,3$ & $1,9,3$ \\
\hline 10 & 0.39 & 0.44 & 0.02 & 0.88 & 0.80 & 0.80 & 1.70 & 1.27 & 1.00 & $10,15,1$ & $1,10,15$ & - \\
\hline 11 & 14.99 & 9.07 & 18.81 & 0.97 & 0.96 & 0.97 & 1.53 & 1.26 & 1.54 & $11,8,5$ & $11,1,2$ & $11,8,5$ \\
\hline 12 & 0.66 & 0.86 & 0.57 & 0.90 & 0.86 & 0.90 & 1.26 & 1.19 & 1.25 & $12,2,5$ & $4,5,12$ & $5,12,2$ \\
\hline 13 & 0.59 & 0.74 & 0.09 & 0.88 & 0.87 & 0.90 & 1.24 & 1.28 & 1.00 & $4,13,1$ & $4,13,1$ & 1,8 \\
\hline 14 & 0.41 & 0.21 & 0.11 & 0.89 & 0.87 & 0.87 & 1.20 & 1.00 & 1.00 & $14,1,7$ & 1 & 1,9 \\
\hline 15 & 0.14 & 0.07 & 0.02 & 0.85 & 0.83 & 0.85 & 1.00 & 1.00 & 1.00 & 1,3 & 1 & 1 \\
\hline
\end{tabular}

The three most commonly observed Kirchhofer map patterns represent the average meridional (map pattern 1) and zonal (map patterns 11 and 8) conditions over the study area. The first pattern accounts for $17.6 \%$ of the observations and is characterized by a strong southwest-northeast height gradient and a trough located north/northeast of the study area. Weak north-south height gradients characterize the second and third most prevalent patterns identified by the analysis (map patterns 11 and 8), which account for approximately $15.0 \%$ and $14.4 \%$ of the observations, respectively. Each of the subsequent patterns accounts for less than $10 \%$ of the observations, although each represents a unique and meaningful synoptic-scale circulation regime.

4.2.2. Comparison of map-pattern frequencies in NNR and transient GCM simulations. The targeted Kirchhofer analysis of the HadCM3 and CGCM2 simulations for 1990-2001 led to the classification of $87.80 \%$ and $89.98 \%$ of simulated days, respectively, and both GCM classifications reproduce the range of map patterns found in the NNR data (Table II). The HadCM3 and CGCM2 classifications also exhibit correlation coefficients for the members of each type that are of similar magnitude as those found in the NNR analysis, suggesting that within-type variability is of similar magnitude as that in the observed record.

The largest discrepancy between the NNR and HadCM3 map-pattern frequencies is that the most common map pattern (pattern 1) occurs too often in HadCM3, while the second and third most common map patterns (patterns 11 and 8) occur too seldom. With the exception of map pattern 8 during winter, the interannual variability of these three most common map patterns is well simulated in all seasons (Figure 5). HadCM3 also slightly overestimates the frequency and interannual variability of map-type 2 during winter and spring. During summer, when the overestimation of map pattern 1 is greatest, the frequencies of several less common map patterns $(2,3,5,8$, and 11) are underestimated, while two additional map patterns occur too often relative to the NNR-derived confidence intervals (4 and 9). Based on the descriptions presented in the previous section, these results suggest that HadCM3 may be biased toward meridional conditions. Accompanying the overestimation of the most common map pattern by HadCM3 is an overestimation of the persistence associated with it. For the other map patterns, HadCM3 simulates the persistence of the map patterns well. Although there are some differences in the progression of the map patterns (Table II), the first-order progression of the most common map patterns is also well simulated by HadCM3. 
(a) DJF

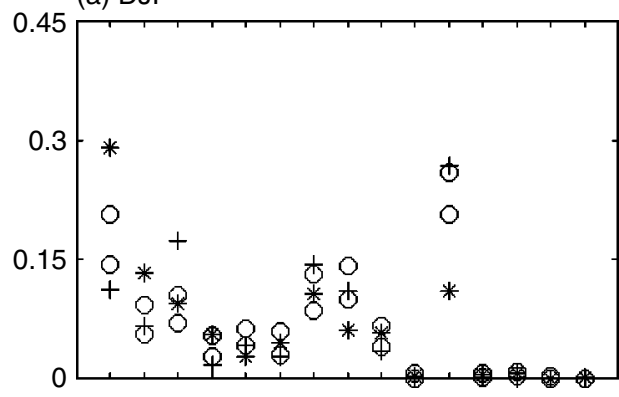

(b) MAM
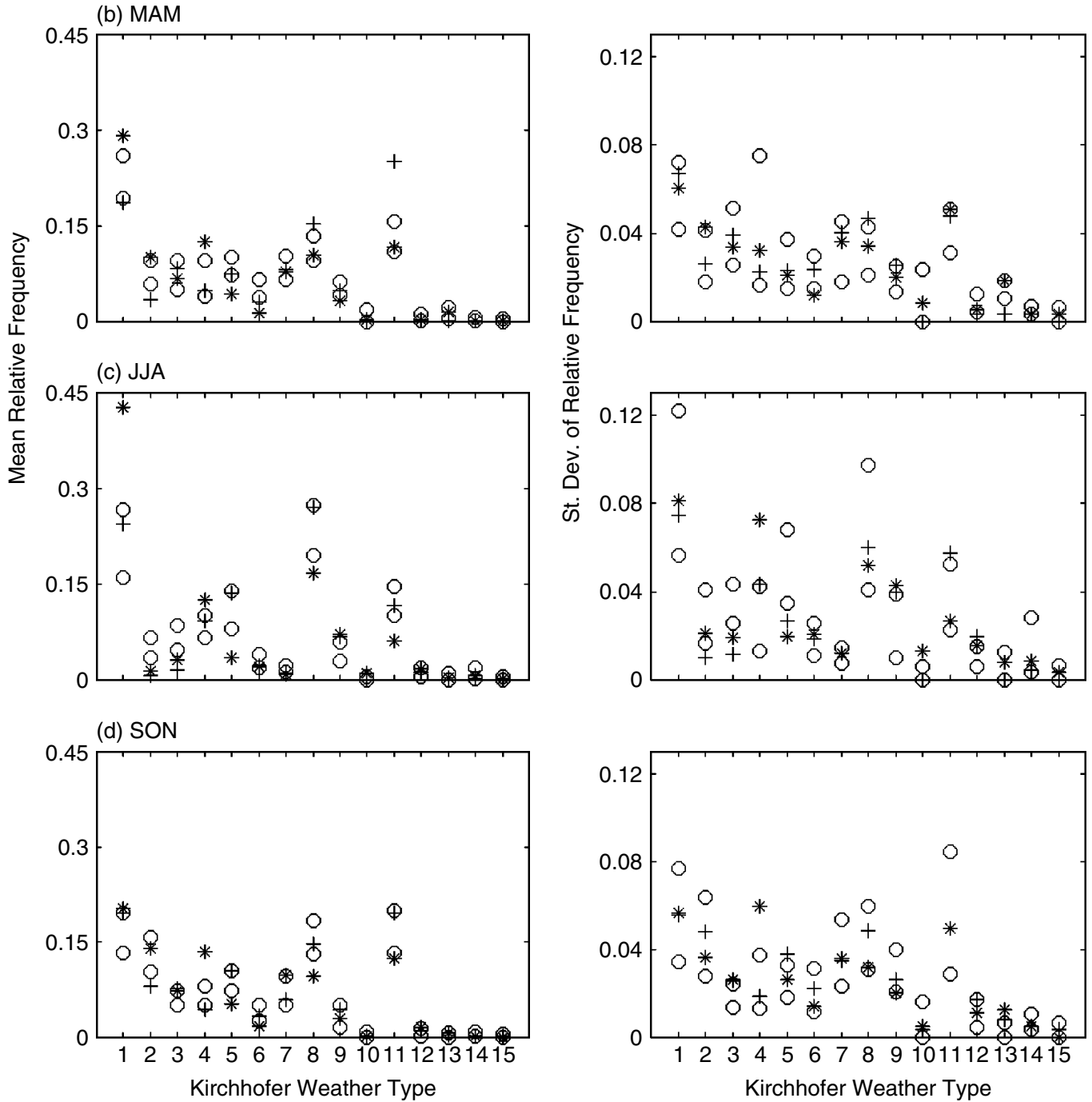
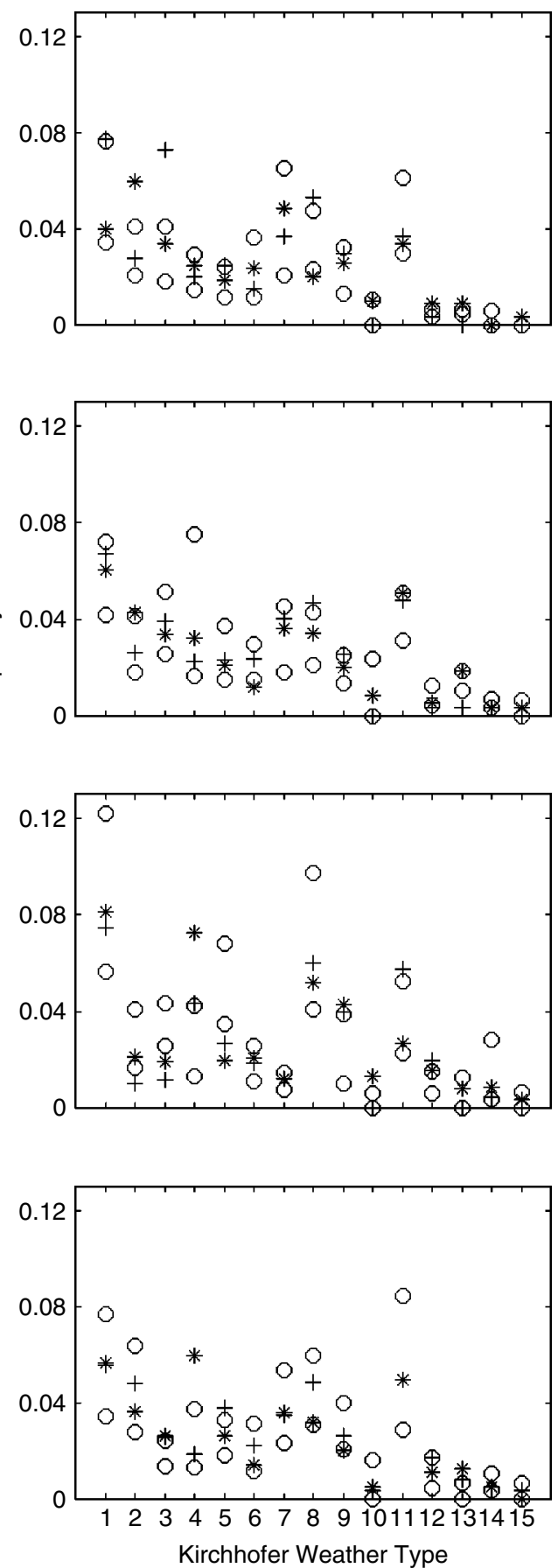

Figure 5. Means (left column) and standard deviations (right column) of the relative frequency of 1990-2001 HadCM3 (*) and CGCM2 $(+)$ map patterns relative to NNR-derived bootstrap confidence intervals $(\mathrm{O})$ : (a) winter, (b) spring, (c) summer, and (d) autumn

In contrast to HadCM3, CGCM2 produces the most common map pattern too seldom during winter and spring, but relative frequencies are within the NNR confidence limits during the other seasons (Figure 5). Summer and autumn mean map-pattern frequencies are within the NNR-derived confidence intervals for most 
map patterns, although frequencies and interannual variability for two of the cyclonic types $(2$ and 3 in summer, 2 in autumn) are lower than those expected from NNR. The largest difference between NNR and CGCM2 during winter is associated with the partitioning of days between two similar map patterns (1 and 3). Both types are associated with low geopotential height anomalies to the northeast of the study region, although map pattern 1 exhibits much stronger geopotential height gradients (Figure 4). The interannual variability of map-type 3 is also overestimated by CGCM2 during the winter. During spring, CGCM2 overestimates the mean frequency of the two zonal map patterns $(8$ and 11) and underestimates the mean frequency of two of the cyclonic map patterns ( 2 and 6). As with HadCM3, the persistence and progression of the CGCM2 map patterns exhibit agreement with the NNR map patterns.

Changes in the map-pattern frequencies during the recent historical record are small relative to differences between the observed (NNR) and simulated (HadCM3, CGCM2) map-pattern frequencies. Nearly all of the map-pattern frequencies from the three 12-year periods preceding the 1990-2001 reference period (1978-1989, 1966-1977, and 1954-1965) lie within the confidence bounds derived from the 1990-2001 NNR data. However, winter occurrences of map pattern 1 were less common and less variable during the reference period than during other portions of the historical record and many of the map patterns exhibit changes in their interannual variability.

Projections from HadCM3 exhibit little evolution in map-pattern frequencies over the twenty-first century. Frequencies of the map patterns during 12-year segments of transient output from HadCM3 (2002-2013, 2014-2025, 2026-2037, 2038-2049, 2050-2061, 2062-2073, 2074-2085, and 2086-2097) lie within, or in close approximation to, the bootstrap confidence intervals derived from the 1990-2001 HadCM3 mappattern frequencies. However, HadCM3 does project increases in the interannual variability of several map patterns, including the three most common map patterns $(1,8$, and 11) during winter. The occurrence of cyclonic conditions associated with map pattern 2 is projected to become less variable during summer and more variable during autumn. Similarly, CGCM2 does not project major changes in the relative frequencies of the map patterns during the twenty-first century, but does indicate that the variability of the frequency of several types may increase. However, in CGCM2 these changes are predominantly associated with zonal or weakly anticyclonic map patterns ( 8 and 11 during winter, 4 during spring and autumn, 5 during summer).

\subsection{Linking synoptic-scale circulation and the teleconnection indices}

Historical analysis of the relationships between NNR map patterns and the NAO index shows that, although several map patterns show preference for a particular phase of the NAO, the differences in proportions are not statistically significant at $\alpha=0.05$ (Table III). When applied to the twenty-first century transient GCM simulations several of the linkages between the teleconnections and map patterns are found to be statistically significant. However, the patterns that are identified as coupled with the NAO differ between the GCMs. Specifically, HadCM3 pattern 1 is linked to the negative phase of the winter NAO and HadCM3 patterns 2, 7 , and 11 are linked to the positive phase of the winter NAO, while CGCM2 patterns 2 and 3 are linked to the negative NAO phase and CGCM2 pattern 8 is more likely under positive NAO conditions.

Given the relative locations of the study region and the NAO centers of action, the weak coupling of the NAO and map patterns is not surprising. Conversely, the PNA centers of action are located much closer to the study area, and therefore exert much more influence on synoptic-scale circulation in this region (Table III). When applied to the 1954-2001 NNR PNA index and map patterns, the two-sample difference of proportions test indicates that several map patterns are more frequent under the positive phase of the PNA. These include map pattern 1 during winter, spring, and autumn and map pattern 3 during winter and autumn. Likewise, multiple map patterns have statistically significant links to the negative phase of the PNA, including map patterns 5 and 11 during winter, spring and autumn, and map pattern 7 during winter and spring.

HadCM3 successfully mimics the link between map pattern 1 and the PNA during winter, spring, and autumn, but fails to produce the link between map pattern 3 and the positive PNA phase during winter (Table III). HadCM3 also reproduces the observed relationships between each of the zonal map patterns and the negative PNA phase. CGCM2 correctly reproduces each of the statistically significant links between the map patterns and PNA phase. Because the sample sizes from the transient GCM simulations are considerably 
Table III. Results of the two-sample difference of proportions tests performed on NNR, HadCM3, and CGCM2 map patterns and NAO and PNA indices indicating preference to a particular phase of the teleconnections. For each season, the table provides the $p$-value (i.e. the probability of observing differences in proportion as extreme or more extreme than those observed if the null hypothesis is true). Table entries are bold if statistically significant at $\alpha=0.05$ for map patterns more likely under the positive teleconnection phase. Table entries are underlined if statistically significant at $\alpha=0.05$ for map patterns more likely under the negative teleconnection phase. A blank entry means that the test was not performed due to small sample size

\begin{tabular}{|c|c|c|c|c|c|c|c|c|c|c|c|c|}
\hline \multirow{2}{*}{$\begin{array}{l}\text { Map } \\
\text { pattern }\end{array}$} & \multicolumn{3}{|c|}{ NAO DJF } & \multicolumn{3}{|c|}{ PNA DJF } & \multicolumn{3}{|c|}{ PNA MAM } & \multicolumn{3}{|c|}{ PNA SON } \\
\hline & NNR & HadCM3 & CGCM2 & NNR & HadCM3 & CGCM2 & NNR & HadCM3 & CGCM2 & NNR & HadCM3 & CGCM2 \\
\hline 1 & 0.24 & $\underline{0.03}$ & 0.21 & 0.00 & 0.00 & 0.00 & 0.01 & 0.00 & 0.00 & 0.00 & 0.00 & 0.00 \\
\hline 2 & 0.41 & 0.04 & $\underline{0.01}$ & 0.08 & $\underline{0.00}$ & $\underline{0.01}$ & 0.13 & $\underline{0.00}$ & 0.07 & 0.05 & $\underline{0.03}$ & $\underline{0.04}$ \\
\hline 3 & 0.14 & 0.26 & $\underline{0.02}$ & 0.00 & 0.29 & 0.00 & 0.08 & 0.65 & 0.00 & 0.01 & 0.00 & 0.00 \\
\hline 4 & 0.22 & 0.08 & 0.68 & 0.17 & $\underline{0.03}$ & 0.29 & 0.08 & 0.07 & $\underline{0.02}$ & 0.06 & $\underline{0.00}$ & $\underline{0.00}$ \\
\hline 5 & 0.57 & 0.14 & 0.14 & $\underline{0.00}$ & $\underline{0.00}$ & $\underline{0.00}$ & $\underline{0.01}$ & $\underline{0.00}$ & $\underline{0.00}$ & $\underline{0.01}$ & $\underline{0.00}$ & $\underline{0.00}$ \\
\hline 6 & 0.23 & 0.05 & 0.11 & 0.24 & 0.40 & 0.27 & 0.66 & 0.57 & 0.59 & 0.22 & 0.27 & 0.02 \\
\hline 7 & 0.20 & 0.04 & 0.15 & $\underline{0.00}$ & $\underline{0.00}$ & $\underline{0.00}$ & $\underline{0.04}$ & $\underline{0.00}$ & $\underline{0.03}$ & 0.25 & 0.07 & 0.29 \\
\hline 8 & 0.27 & 0.53 & 0.01 & $\overline{0.63}$ & 0.30 & $\overline{0.05}$ & 0.56 & $\overline{0.54}$ & 0.67 & 0.66 & 0.53 & 0.48 \\
\hline 9 & 0.50 & 0.32 & 0.35 & 0.69 & 0.15 & 0.04 & 0.50 & 0.50 & 0.61 & 0.55 & 0.61 & 0.22 \\
\hline 10 & & 0.41 & & & & & 0.07 & 0.16 & & & 0.21 & \\
\hline 11 & 0.14 & 0.00 & 0.15 & $\underline{0.00}$ & $\underline{0.00}$ & $\underline{0.00}$ & $\underline{0.00}$ & $\underline{0.02}$ & $\underline{0.00}$ & $\underline{0.01}$ & $\underline{0.03}$ & $\underline{0.04}$ \\
\hline 12 & & & & & & & & & & 0.58 & 0.14 & 0.22 \\
\hline 13 & & 0.65 & & & 0.63 & & & 0.30 & & & 0.26 & \\
\hline 14 & & & & & & & & & & & 0.41 & 0.64 \\
\hline 15 & & & & & & & & & & & & \\
\hline
\end{tabular}

larger than those in the historical NNR data, each of the GCMs also identifies statistically significant linkages between the PNA index and the map patterns that are not statistically significant according to the analyses performed on the NNR data.

Examination of the links between the teleconnections and the map patterns as simulated by the GCMs provides some insight into the differences between the classifications described in Section 4.2.2. For example, the GCM-simulated links between the NAO and map patterns that are not evident in the historical NNR data may provide a partial explanation for the differences in the winter NNR and GCM-derived map-pattern classifications. Further study is needed to prescribe causality to these results.

\section{CONCLUDING REMARKS}

Reliable regional climate projections for the midlatitudes are critically dependent on the accuracy of the depiction of large-scale climate within GCMs. We have presented an evaluation of GCM simulations of two prominent teleconnections, the NAO and PNA, as well as synoptic-scale map patterns in the Midwest region of the United States and their links to the teleconnection indices. The analyses presented here indicate that differences between GCM and NNR realizations of both the NAO and PNA for the reference period (1990-2001) are smaller than both changes in the observed historical record and prognostic changes for approaching decades. Despite the relatively good correspondence between the NNR and GCMs with respect to the synoptic-scale map patterns within the study region, differences between NNR and both HadCM3 and CGCM2 map patterns in the reference period (1990-2001) are demonstrated to be of comparable or greater magnitude than recent historical changes (based on 1954-2001 NNR map patterns) and prognostic changes from the HadCM3 and CGCM2 simulations (based on twenty-first century transient GCM simulations). Hence, the inference that must be drawn from this analysis is that GCM-derived projections of the synoptic climate of this region remain uncertain. This finding does not indicate a lack of evolution in the map patterns, but the 
results do suggest that the evolution does not exceed the differences between NNR and GCM-derived map patterns during the reference period.

The results of this study have major implications for studies which downscale GCM output for regional climate change assessments. While many downscaling studies rely on changes in the frequency of circulation types to provide additional information about potential climate change (see Giorgi et al., 2001 and references therein), our findings indicate only small changes in circulation-based map-pattern frequencies within the Midwest region of the United States during the twenty-first century. Hence, map-pattern classifications may provide little additional regional climate change information beyond that provided by the direct use of GCM output.

It is important to note that there are two major caveats to the findings presented here. First, we examined 12year time windows to ensure direct comparability with the overlap period for NNR, HadCM3, and CGCM2. Even with the implementation of the bootstrap resampling methodology, these time periods do not represent a full climatology, and cannot account for decadal variability in the teleconnections and map patterns. Second, it should be emphasized that the findings documented herein were specifically based on simulations conducted using a single emissions scenario (SRES A2) and two GCMs. Just as the results could differ for other periods, they may also differ if other GCMs or emissions scenarios were used. Future work will address this issue by evaluating and comparing the performance of additional GCMs under various emissions scenarios.

\section{ACKNOWLEDGEMENTS}

This research was supported in part by the Office of Science (BER), U.S. Department of Energy, through the National Institute for Global Environmental Change under Cooperative Agreement No. DE-FC03-90ER61010 via a grant to Pryor, Barthelmie and Carreiro. The computational component of the research was made possible by the following grants to Indiana University from IBM, inc. (Shared University Research) and the National Science Foundation (grant \# 0116050). JS also gratefully acknowledges a Dissertation Year Fellowship from Indiana University. HadCM3 data has been supplied by the Climate Impacts LINK Project (DERFA Contract EPG 1/1/124) on behalf of the Hadley Centre and U.K. Meteorological Office. NCEP/NCAR mean SLP data were provided by the NOAA-CIRES Climate Diagnostics Center, Boulder, Colorado, USA, from their website at http://www.cdc.noaa.gov. We also wish to acknowledge useful discussions regarding statistical applications with Dr Scott Robeson, and the comments of two anonymous reviewers.

\section{REFERENCES}

Barnston AG, Livezey RE. 1987. Classification, seasonality, and persistence of low-frequency atmospheric circulation patterns. Monthly Weather Review 115: 1083-1126.

Blackmon ML, Lee Y-H, Wallace JM, Hsu H-H. 1984. Time variation of 500-mb height fluctuations with long, intermediate, and short time scales as deduced from lag-correlation statistics. Journal of Atmospheric Science 41: 961-979.

Bojariu R, Gimeno L. 2003. The role of snow cover fluctuations in multiannual NAO persistence. Geophysical Research Letters 30: 1156-1159.

Covey C, AchutaRao KM, Cubasch U, Jones P, Lambert SJ, Mann ME, Phillips TJ, Taylor KE. 2003. An overview of results from the coupled model intercomparison project. Global and Planetary Change 37: 103-133.

Efron B. 1982. The Jackknife, the Bootstrap, and Other Resampling Plans. CBMS-NSF Regional Conference Series in Applied Mathematics, Monograph 38, Society for Industrial and Applied Mathematics, Philadelphia, PA, USA.

El-Kadi AKA, Smithson PA. 1992. Atmospheric classifications and synoptic climatology. Progress in Physical Geography 16: $432-455$.

Flato GM, Boer GJ. 2001. Warming asymmetry in climate change simulations. Geophysical Research Letters 28: $195-198$.

Flato G, Boer GJ, Lee WG, McFarlane NA, Ramsden D, Reader MC, Weaver AJ. 2000. The Canadian centre for climate modelling and analysis global coupled model and its climate. Climate Dynamics 16: 451-467.

Gates W, Boyle JS, Covey C, Dease C, Doutriaux C, Drach R, Fiorino M, Glecker P, Hnilo J, Marlais S, Phillips T, Potter G, Santer B, Sperber K, Taylor K, Williams D. 1999. An overview of the results of the Atmospheric Model Intercomparison Project (AMIP1). Bulletin of the American Meteorological Society 80: 29-55.

Giorgi F, Hewitson B, Christensen J, Hulme M, von Storch H, Whetton P, Jones R, Mearns L, Fu C. 2001. Regional Climate Information - Evaluation and Projections. Climate Change 2001: The Scientific Basis. Contribution of Working Group I to the Third Assessment Report of the Intergovernmental Panel on Climate Change. Houghton JT, Ding Y, Griggs DJ, Noguer M, van der Linden PJ, Dai X, Maskell K, Johnson CA (eds). Cambridge, New York, Cambridge University Press: 881.

Glowienka-Hense R. 1990. The North Atlantic oscillation in the Atlantic-European SLP. Tellus 42A: $497-507$.

Gordon C, Cooper C, Senior CA, Banks H, Gregory JM, Johns TC, Mitchell JFB, Wood RA. 2000. The simulation of SST, sea ice extents and ocean heat transports in a version of the Hadley Centre coupled model without flux adjustments. Climate Dynamics 16: $147-168$. 
Hurrell JW. 1995. Decadal trends in the North Atlantic Oscillation regional temperatures and precipitation. Science 269: 676-679. Hurrell JW, Van Loon H. 1997. Decadal variations in climate associated with the North Atlantic oscillation. Climatic Change 36: $301-326$.

IPCC. 2000. Special Report on Emissions Scenarios. Cambridge University Press: Cambridge, 612.

IPCC. 2001. Climate Change 2001: The Scientific Basis. Contribution of Working Group I to the Third Assessment Report of the Intergovernmental Panel on Climate Change. Houghton JT, Ding Y, Griggs DJ, Noguer M, van der Linden PJ, Dai X, Maskell K, Johnson CA (eds). Cambridge, New York, Cambridge University Press: 881.

Kalnay E, Kanamitsu M, Kistler R, Collins W, Deaven D, Gandin L, Iredell M, Saha S, White G, Woollen J, Zhu Y, Chelliah M, Ebisuzaki W, Higgins W, Janowiak J, Mo KC, Ropelewski C, Wang J, Leetmaa A, Reynolds R, Jenne R, Joseph D. 1996. The NCEP/NCAR 40-year reanalysis project. Bulletin of the American Meteorological Society 77: 437-470.

Kang L-S, Jin K, Lau K-M, Shukla J, Krishnamurthy V, Schubert SD, Waliser DE, Stern WF, Satyan V, Kitoh A, Meehl GA, Kanamitsu M, Galin VY, Sumi A, Wu G, Liu Y, Kim J-K. 2002. Intercomparison of atmospheric GCM simulated anomalies associated with the 1997/98 El Nino. Journal of Climate 15: 2791-2805.

Kirchhofer W. 1974. Classification of European 500 mb Patterns. Schwiezerische Meteorologische Anstalt, vol. 43. Institut Suisse de Meteorologie: Zurich, 1-16.

Kistler R, Kalnay E, Collins W, Saha S, White G, Woollen J, Chelliah M, Ebisuzaki W, Kanamitsu M, Kousky V, van den Dool H, Jenne R, Fiorino M. 2001. The NCEP-NCAR 50-year reanalysis: Monthly means CD-ROM and documentation. Bulletin of the American Meteorological Society 82: 247-267.

Kushnir Y. 1994. Interdecadal variations in North Atlantic sea surface temperature and associated atmospheric conditions. Journal of Climate 7: 141-157.

Lapp S, Byrne J, Kienzle S, Townshend I. 2002. Linking global circulation model synoptics and precipitation for western North America. International Journal of Climatology 22: 1807-1817.

Leathers DJ, Yarnal B, Palecki MA. 1991. The Pacific North-American teleconnection pattern and United-States climate. 1. Regional temperature and precipitation associations. Journal of Climate 4: 517-528.

Leathers DJ, Palecki MA. 1992. The Pacific North-American teleconnection pattern and United-States climate. 2 temporal characteristics and index specification. Journal of Climate 5: 707-716.

Lund IA. 1963. Map-pattern classification by statistical methods. Journal of Applied Meteorology 2: 56-65.

McAveney BJ, Covey C, Joussaume S, Kattsov V, Kitoh A, Ogana W, Pitman AJ, Weaver AJ, Wood RA, Zhao Z-C. 2001. Model Evaluation. Climate Change 2001: The Scientific Basis. Contribution of Working Group I to the Third Assessment Report of the Intergovernmental Panel on Climate Change. Houghton JT, Ding Y, Griggs DJ, Noguer M, van der Linden PJ, Dai X, Maskell K, Johnson CA (eds). Cambridge, New York, Cambridge University Press: 881.

McKendry IG, Steyn DG, McBean G. 1995. Validation of synoptic circulation patterns simulated by the Canadian climate centre general circulation model for Western North America. Atmosphere-Ocean 33: 809-825.

Osborn TJ, Briffa KR, Tett SFB, Jones PD. 1999. Evaluation of the North Atlantic oscillation as simulated by a coupled climate model. Climate Dynamics 15: 685-702.

Ott RL. 1993. An Introduction to Statistical Methods and Data Analysis. Duxbury Press: Belmont.

Pan Z, Christensen J, Arritt RW, Gutowski W, Takle ES, Otieno F. 2001. Evaluation of uncertainties in regional climate change simulations. Journal of Geophysical Research 106: 17735-17751.

Pope VD, Gallani ML, Rowntree PR, Stratton RA. 2000. The impact of new physical parameterizations in the Hadley Centre climate model: HadAM3. Climate Dynamics 16: 123-146.

Pryor SC, Barthelmie RJ. 2003. Long-term trends in near-surface flow over the Baltic. International Journal of Climatology 23: $271-289$.

Renshaw AC, Rowell DP, Folland CK. 1998. Wintertime low-frequency weather variability in the North Pacific-American section 1949-93. Journal of Climate 11: 1073-1093.

Schubert S. 1998. Downscaling local extreme temperature changes in south-eastern Australia from the CSIRO MARK2 GCM. International Journal of Climatology 18: 1419-1438.

Sheridan SC. 2003. North American weather-type frequency and teleconnection indices. International Journal of Climatology 23: $27-45$.

Stephenson DB, Pavan V. 2003. The North Atlantic oscillation in coupled climate models: a CMIP1 evaluation. Climate Dynamics 20: 381-399.

Stocker TF, Clarke GKC, Le Treut H, Lindzen RS, Meleshko VP, Mugara RK, Palmer TN, Pierrehumbert RT, Sellers PJ, Trenberth KE, Willebrand J. 2001. Physical Climate Processes and Feedbacks.Climate Change 2001: The Scientific Basis. Contribution of Working Group I to the Third Assessment Report of the Intergovernmental Panel on Climate Change. Houghton JT, Ding Y, Griggs DJ, Noguer M, van der Linden PJ, Dai X, Maskell K, Johnson CA (eds). Cambridge, New York, Cambridge University Press: 881 .

Tourre Y, Rajagopalan B, Kushnir Y. 1999. Dominant patterns of climate variability in the Atlantic Ocean during the last 136 years. Journal of Climate 12: 2285-2299.

Visbeck M, Chassignet EP, Curry RG, Delworth TL, Dickson RR, Krahmann G. 2003. The Ocean's Response to North Atlantic Oscillation Variability. The North Atlantic Oscillation: Climatic Significance and Environmental Impact, AGU Geophysical Monograph 134. AGU: Washington, DC, 113-146.

von Storch H, Zwiers FW. 1999. Statistical Analysis in Climate Research. Cambridge University Press: Cambridge.

Wallace JM, Gutzler DS. 1981. Teleconnections in the geopotential height field during the Northern Hemisphere winter. Monthly Weather Review 109: 784-812.

Wilks DS. 1995. Statistical Methods in the Atmospheric Sciences. Academic Press: San Diego.

Willmott CJ. 1987. Synoptic weather map classification: Correlation versus sums-of-squares. The Professional Geographer 39: $205-207$.

Yarnal B. 1985. A $500 \mathrm{mb}$ synoptic climatology of Pacific Northwest coast winters in relation to climatic variability, 1948-1949 to 1977-1978. Journal of Climatology 5: 237-252.

Yarnal B. 1993. Synoptic Climatology in Environmental Analysis. Belhaven Press: London.

Yarnal B, Leathers DJ. 1988. Relationships between interdecadal and interannual climatic variations and their effect on Pennsylvania climate. Annals of the Association of American Geographers 78: 624-641. 